NASA Contractor Report 186019

\title{
An Aircraft Model for the AIAA Controls Design Challenge
}

Randal W. Brumbaugh

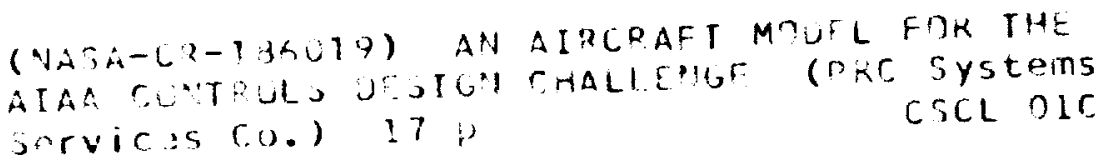
(NASA-LZ-13RU19) AN AIRCPAFT MOUFL FOK THE jorvic:s $(0) \quad$.17 :

Contract NAS 2-12722

December 1991

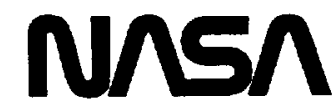

National Aeronautics and

Space Administration 

NASA Contractor Report 186019

\section{An Aircraft Model for the AIAA Controls Design Challenge}

Randal W. Brumbaugh

PRC Inc.,

Eowwards, California

Prepared for

NASA Dryden Flight Research Facility

Edwards, California

Under Contract NAS 2-12722

1991

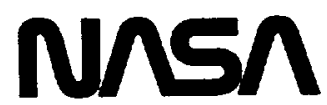

National Aeronautics and

Space Administration

Dryden Flight Research Facility

Edwards, California 93523-0273 


\title{
An Aircraft Model for the AIAA Controls Design Challenge
}

\author{
Randal W. Brumbaugh* \\ PRC Inc. \\ Edwards, California
}

\begin{abstract}
This paper describes a generic, state-of-the-art, highperformance aircraft model, including detailed, fullenvelope, nonlinear aerodynamics, and full-envelope thrust and first-order engine response data. While this model was primarily developed for the AIAA Controls Design Challenge, the availability of such a model provides a common focus for research in aeronautical control theory and methodology. This paper also describes an implementation of this model using the FORTRAN computer language, associated routines furnished with the aircraft model, and techniques for interfacing these routines to external procedures. Figures showing vehicle geometry, surfaces, and sign conventions are included.
\end{abstract}

\section{Nomenclature}

$$
\begin{array}{ll}
A & \text { axial force, } l b \\
a & \text { speed of sound in air, ft/sec } \\
a_{n} & \text { normal acceleration, } g \\
a_{n x} & \begin{array}{l}
x \text {-body axis accelerometer output, accel- } \\
\text { erometer at center of gravity, } g
\end{array} \\
a_{n y} & \begin{array}{l}
y \text {-body axis accelerometer output, accel- } \\
\text { erometer at center of gravity, } g
\end{array} \\
a_{n x} & z \text {-body axis accelerometer output, accel- } \\
& \text { erometer at center of gravity, } g \\
a_{x} & \text { acceleration along the } x \text {-body axis, } g \\
a_{y} & \text { acceleration along the } y \text {-body axis, } g \\
a_{z} & \text { acceleration along the } z \text {-body axis, } g \\
b & \text { wingspan, } \mathrm{ft} \\
C & \text { force or moment coefficient } \\
C_{D} & \text { coefficient of drag } \\
C_{L} & \text { coefficient of lift } \\
C_{\ell} & \text { coefficient of rolling moment }
\end{array}
$$

\begin{tabular}{|c|c|}
\hline$C_{m}$ & coefficient of pitching moment \\
\hline$C_{*}$ & coefficient of yawing moment \\
\hline$C_{y}$ & coefficient of sideforce \\
\hline$\overline{\boldsymbol{c}}$ & mean aerodynamic chord, $\mathrm{ft}$ \\
\hline$D$ & drag force, lb \\
\hline det & determinant of matrix \\
\hline$E$, & specific energy, ft \\
\hline fpa & flightpath acceleration, $g$ \\
\hline$G$ & actuator transfer function \\
\hline$g$ & acceleration due to gravity, $\mathrm{ft} / \mathrm{sec}^{2}$ \\
\hline $\boldsymbol{h}$ & altitude, $\mathrm{ft}$ \\
\hline$\ddot{h}$ & vertical acceleration, $\mathrm{ft} / \mathrm{sec}^{2}$ \\
\hline$I$ & aircraft inertia tensor, slug- $\mathrm{ft}^{2}$ \\
\hline$I_{e}$ & rotational inertia of the engine, slug- $\mathrm{ft}^{2}$ \\
\hline$I_{x}$ & $x$-body axis moment of inertia, slug- $\mathrm{ft}^{2}$ \\
\hline$I_{x y}$ & $x-y$ body axis product of inertia, slug $-\mathrm{ft}^{2}$ \\
\hline$I_{x z}$ & $x-z$ body axis product of inertia, slug $-\mathrm{ft}^{2}$ \\
\hline$I_{y}$ & $y$-body axis moment of inertia, slug- $\mathrm{ft}^{2}$ \\
\hline$I_{y x}$ & $y-z$ body axis product of inertia, slug- $\mathrm{ft}^{2}$ \\
\hline$I_{z}$ & $z$-body axis moment of inertia, slug- $\mathrm{ft}^{2}$ \\
\hline$K$ & aerodynamic constant \\
\hline$L$ & $\begin{array}{l}\text { total body axis aerodynamic rolling moment, ft-lb; } \\
\text { or total aerodynamic lift, lb }\end{array}$ \\
\hline$\ell$ & generalized length, $\mathrm{ft}$ \\
\hline$M$ & $\begin{array}{l}\text { Mach number; or total body axis aerodynamic } \\
\text { pitching moment, ft-1b }\end{array}$ \\
\hline$m$ & aircraft total mass, slug \\
\hline$m_{e}$ & mass of engine \\
\hline$N$ & $\begin{array}{l}\text { normal force, lb; or total body axis aerodynamic } \\
\text { yawing moment, ft-lb }\end{array}$ \\
\hline$n$ & load factor \\
\hline$P_{\varepsilon}$ & specific power, ft/sec \\
\hline
\end{tabular}

-Electrical engineer, member AIAA.

This paper is a work of the U.S. Government and is not subject to copyright protection in the United Stutes. 


\begin{tabular}{|c|c|}
\hline $\mathbf{p}$ & $\mathrm{roll}$ rate, rad/sec; or pressure, $\mathrm{lb} / \mathrm{ft}^{2}$ \\
\hline po & ambient pressure, $\mathrm{lb} / \mathrm{ft}^{2}$ \\
\hline pt & total pressure, lb/ft ${ }^{2}$ \\
\hline 9 & pitch rate, $\mathrm{rad} / \mathrm{sec}$ \\
\hline $\bar{q}$ & dynamic pressure, $\mathrm{lb} / \mathrm{ft}^{2}$ \\
\hline$q_{c}$ & impact pressure, lb/ft ${ }^{2}$ \\
\hline Re & Reynolds number \\
\hline$R e^{\prime}$ & Reynolds number per unit length, $\mathrm{ft}^{-1}$ \\
\hline $\boldsymbol{r}$ & yaw rate, rad/sec \\
\hline$S$ & wing planform area, $\mathrm{ft}^{2}$ \\
\hline 8 & complex frequency \\
\hline $\boldsymbol{T}$ & $\begin{array}{l}\text { ambient temperature, } \mathrm{K} \text {; or total angular } \\
\text { momentum slug- } \mathrm{ft}^{2} / \mathrm{sec}^{2} \text {; or thrust, lb }\end{array}$ \\
\hline$T_{t}$ & total temperature, $\mathrm{K}$ \\
\hline$u$ & velocity in $x$-axis direction, $\mathrm{ft} / \mathrm{sec}$ \\
\hline V & total velocity, fusec \\
\hline$V_{c}$ & calibrated airspeed, kn \\
\hline Ve & equivalent airspeed, kn \\
\hline $\boldsymbol{v}$ & velocity in $y$-axis direction, $\mathrm{ft} / \mathrm{sec}$ \\
\hline$W$ & vehicle weight, lb \\
\hline$w$ & velocity in $z$-axis direction, $\mathrm{ft} / \mathrm{sec}$ \\
\hline$X$ & total force along the $x$-body axis, lb \\
\hline$X_{\mathbf{T}}$ & thrust along the $x$-body axis, lb \\
\hline$Y$ & sideforce, $\mathbf{l b}$ \\
\hline$Y_{T}$ & thrust along the $y$-body axis, lb \\
\hline$Z$ & total force along the $z$-body axis, lb \\
\hline$Z_{T}$ & thrust along the $z$-body axis, lb \\
\hline$\alpha$ & angle of attack, rad \\
\hline$\beta$ & angle of sideslip, rad \\
\hline$\gamma$ & flightpath angle, rad \\
\hline$\Delta r$ & $\begin{array}{l}\text { displacement of aerodynamic reference } \\
\text { point from center of gravity }\end{array}$ \\
\hline$\Delta x$ & $\begin{array}{l}\text { displacement from center of gravity } \\
\text { along } x \text {-body axis, ft }\end{array}$ \\
\hline$\Delta y$ & $\begin{array}{l}\text { displacement from center of gravity } \\
\text { along } y \text {-body axis, } f t\end{array}$ \\
\hline$\Delta z$ & $\begin{array}{l}\text { displacement from center of gravity } \\
\text { along } z \text {-body axis, } \mathrm{ft}\end{array}$ \\
\hline$\delta_{\boldsymbol{A}}$ & differential aileron command \\
\hline$\delta_{\mathrm{D}}$ & differential stabilator command \\
\hline$\delta_{\mathbf{H}}$ & symmetric stabilator command \\
\hline$\delta_{R}$ & directional command \\
\hline$\delta_{j k}$ & Kronecker delta \\
\hline
\end{tabular}

$\theta$ pitch angle, rad

$\mu \quad$ coefficient of viscosity

$\rho$ density of air, slug/ft

$\Sigma L \quad$ total body axis rolling moment, $\mathrm{ft}-\mathrm{lb}$

$\Sigma M$ total body axis pitching moment, $\mathrm{ft}-\mathrm{lb}$

$\Sigma N \quad$ total body axis yawing moment, $\mathrm{ft}-\mathrm{lb}$

$\phi \quad$ roll angle, rad

$\phi_{L} \quad$ tilt angle of acceleration nocmal to the flightpath from the vertical plane, rad

$\psi \quad$ heading angle, rad
$\omega \quad$ total rotational velocity of the vehicle

\section{Superseripts}

- derivative with respect to time

\section{Subecripts}

\begin{tabular}{|c|c|}
\hline $\mathbf{A}$ & aileron \\
\hline or & aerodynamic reference point \\
\hline D & differential stabilator \\
\hline$D$ & total drag \\
\hline $\boldsymbol{E}$ & engine \\
\hline $\mathbf{H}$ & symmetric stabilator \\
\hline $\boldsymbol{h}$ & altitude \\
\hline,$i$ & measurement not at aerodynamic reference \\
\hline$L$ & total lift \\
\hline $\boldsymbol{\ell}$ & rolling moment \\
\hline$M$ & Mach number \\
\hline$m$ & pitching moment \\
\hline$n$ & yawing moment \\
\hline 0 & offset from center of gravity \\
\hline $\mathbf{p}$ & roll rate \\
\hline$q$ & pitch rate \\
\hline $\mathbf{R}$ & rudder \\
\hline $\boldsymbol{r}$ & yaw rate \\
\hline$s$ & stability axis \\
\hline $\boldsymbol{x}$ & along the $x$-body axis \\
\hline$Y$ & sideforce \\
\hline$y$ & along the $y$-body axis \\
\hline$z$ & along the $z$-body axis \\
\hline $\mathbf{0}$ & standard day, sea level conditions \\
\hline
\end{tabular}




\section{Introduction}

\section{Background and History}

This paper describes the structure and implementation of a high-performance aircraft model. The model was developed for the AIAA Controls Design Challenge, but is intended to be useful for a variety of controls and guidance applications. Model definition and implementation are covered in separate sections.

The AIAA Controls Design Challenge provides an opportunity for participants to apply control system design methodologies to a realistic, nonlinear aircraft model. Any design which performs the control task is acceptable, but innovative or unusual approaches have been encouraged. The challenge is a two-year competition. Control designs are judged according to their ability to control the model during a level acceleration and 3-g turn maneuver at four specified flight conditions.

The model integrates several components. Existing pieces were used whenever possible and modified to facilitate integration. The result is that most of the model implementation is based directly on proven and reliable components, although the resulting model is not completely representative of any particular aircraft. Because of the mixed history of the model, some aspects may appear to resemble actual aircraft. The user is warned against making any assumptions based on these appearances.

\section{Model Characteristics}

The model is a collection of modules, each performing a specific function. The primary modules are the aircraft actuator and surface command inputs, aircraft mass and geometry modeling, the equations of motion, the atmospheric model, the aerodynamics, the propulsion system, and the observation variable modeling. Each major module is described in the following sections. Figure 1 shows how the modules would be connected together with user synthesized control laws to form a complete system model.

\section{Aircraft Description}

The aircraft modeled is a high-performance, supersonic vehicle representative of current-day fighters. It is powered by two afterburning turbofan engines, each capable of producing approximately $32,000 \mathrm{lb}$ of thrust. A three-view of the aircrat is shown in Fig. 2, including control surfaces and locations.

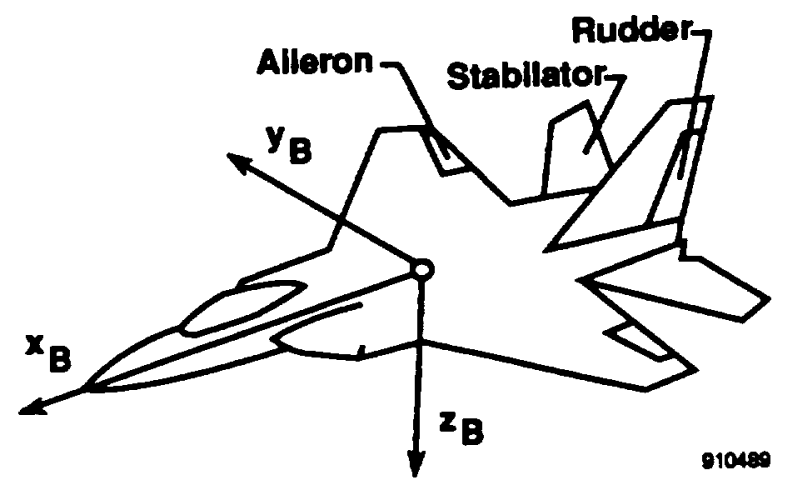

Fig. 2 Three view of aircraft and control surfaces.

The operational envelope for this vehicle, for trimmed, straight-and-level, $1-g$ flight is shown in Fig. 3 for the specified weight of $45,000 \mathrm{lb}$. The envelope includes a maximum Mach number $(M)$ of 2.3 and an altitude limit in the 50,000 - to 60,000 -ft range. Mass and geometry parameters are given in Table 1 .

The aircraft primary flight-control surfaces consist of horizontal stabilators which are capable of symmetric or differential movement, conventional ailerons, and a single

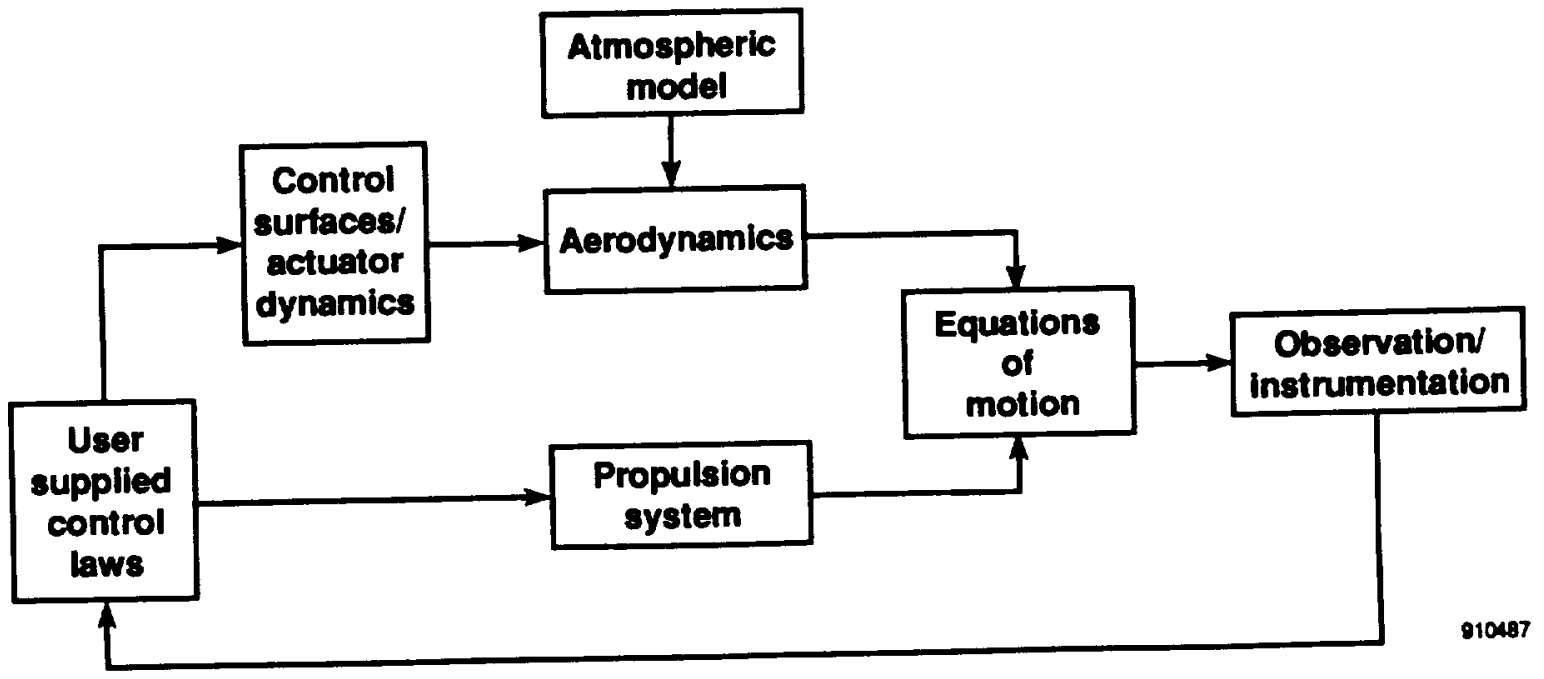

Fig. 1 Modular structure of the model. 
Table 1. Mass and geometry characteristics.

\begin{tabular}{lcr}
\hline \hline \multicolumn{1}{c}{ Parameter } & Symbol & \multicolumn{1}{c}{ Value } \\
\hline Wing area & $S$ & $608.0 \mathrm{ft}^{2}$ \\
Wing span & $b$ & $42.8 \mathrm{ft}$ \\
Mean aerodynamic chord & $\bar{c}$ & $15.95 \mathrm{ft}$ \\
Vehicle weight & $W$ & $45,000.0 \mathrm{lb}$ \\
Moments of inertia & & \\
(Roll) & $I_{x}$ & $28,700.0$ slug/ $\mathrm{ft}^{2}$ \\
(Pitch) & $I_{y}$ & $165,100.0$ slug/ $\mathrm{f}^{2}$ \\
(Yaw) & $I_{z}$ & $187,900.0$ slug/ $\mathrm{ft}^{2}$ \\
Products & $I_{x z}$ & -520.0 slug/ $/ \mathrm{f}^{2}$ \\
& $I_{x y}$ & 0.0 slug/ $\mathrm{ft}^{2}$ \\
& $I_{y z}$ & 0.0 slug/ $/ \mathrm{ft}^{2}$ \\
\hline \hline
\end{tabular}

vertical rudder. The individual surface position limits, rate limits, and sign conventions for positive deflection are detailed in Table 2. The equations in Table 3 define the individual surface deflections in terms of command inputs. There are a total of five actuators; two aileron, two stabilator, and one rudder. The model includes identical actuators for all surfaces. These actuators are rate limited at $24 \mathrm{deg} / \mathrm{sec}$ and have a first-order response modeled by

$$
G(s)=\frac{20}{s+20}
$$

A block diagram of the actuator model is shown in Fig. 4. The command inputs to the aileron and stabilator surfaces are differential and symmetric commands, which are separated into inputs to each of the surface actuator models. The resulting surface positions are then recombined to obtain the command response. This is shown for the stabilators in Fig. 5. Because of the nonlinearities in the stabilator command path, the commands will interact in ways which are not easily predicted. This interaction is shown in Figs. 6 and 7.

\section{Aerodynamic Model}

The aerodynamics are modeled for the full vehicle envelope using multidimensional tables and linear interpolation to form nonlinear function generators. In general, these aerodynamic quantities are functions of $M$ and some combination of angle of attack $(\alpha)$, angle of sideslip $(\beta)$, and symmetric stabilator deflection.
Table 3. Surface deflection definition equations.

\begin{tabular}{ccc}
\hline \hline Surface & Defiection definition & $\begin{array}{c}\text { Rate limit } \\
\text { deg/sec }\end{array}$ \\
\hline$\delta_{A_{m}}$ & $\delta_{A} \div 2$ & 24 \\
$\delta_{A_{1}}$ & $-\delta_{A} \div 2$ & 24 \\
$\delta_{H_{n}}$ & $\left(2 \delta_{H}-\delta_{D}\right) \div 2$ & 24 \\
$\delta_{H}$ & $\left(2 \delta_{H}+\delta_{D}\right) \div 2$ & 24 \\
$\delta_{R}$ & $\delta_{R}$ & 24 \\
\hline \hline
\end{tabular}

The equations defining the aerodynamic model provide nondimensional force and moment coefficients. The longitudinal parameters are in the stability axis system; the lateral-directional parameters are given with respect to the body axis system.

The equations used for this model are given in the following

$$
\begin{aligned}
& C_{L_{\text {miv }}}=C_{L_{\text {malc }}}+\Delta C_{L_{\text {s, }} n_{z}} \\
& C_{\text {mins }}=C_{\text {menex }}+\Delta C_{m_{\text {ma }}} n_{\text {m }} \\
& +\frac{\bar{c}}{(2 V)}\left(C_{m, q}+C_{m,} \dot{\alpha}+C_{L_{\text {max }}} \Delta N_{0}\right) \\
& C_{D_{\text {TNS }}}=C_{D}+\Delta C_{D_{\text {dut }}}+\Delta C_{D_{\text {men }}}
\end{aligned}
$$

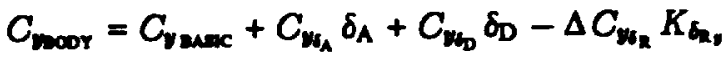

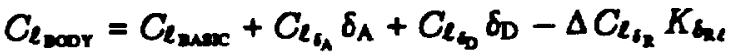

$$
\begin{aligned}
& +\frac{b}{(2 V)}\left(C_{\ell_{p} p}+C_{\ell_{r} r}\right) \\
& C_{\mathrm{n} \text { moor }}=C_{n_{\text {max }}}+C_{\mathrm{nd}_{\mathrm{A}}} \delta_{\mathrm{A}}+C_{\mathrm{n} \mathrm{d}_{\mathrm{D}}} \delta_{\mathrm{D}}+\Delta C_{\mathrm{nd}_{\mathrm{R}}} K_{\delta_{\mathrm{R}}} \\
& +\frac{b}{(2 V)}\left(C_{n, p}+C_{m, r}\right)
\end{aligned}
$$

The terms in the equations containing $C, \Delta C, \Delta N$, or $K$ are outputs from the function generation routines, and are either calculated by linear interpolation of tabular data or by direct calculation. The source of the functional coefficients is shown in Table 4.

\section{Propulsion System Model}

The propulsion system model consists of two distinct engine models. The engines are similar, but not identical; the thrust produced for identical throttle settings is not

Table 2. Command input limits and sign conventions.

\begin{tabular}{lccl}
\hline \hline \multicolumn{1}{c}{ Command name } & Symbol & Limits, deg & Positive sign convention \\
\hline Aileron & $\delta_{\mathrm{A}}$ & \pm 20 & Left trailing edge down \\
Symmetric stabilator & $\delta_{\mathrm{H}}$ & $+15 /-25$ & Trailing edge down \\
Differential stabilator & $\delta_{\mathrm{D}}$ & \pm 20 & Left trailing edge down \\
Rudder & $\delta_{\mathrm{R}}$ & \pm 30 & Trailing edge left \\
\hline \hline
\end{tabular}




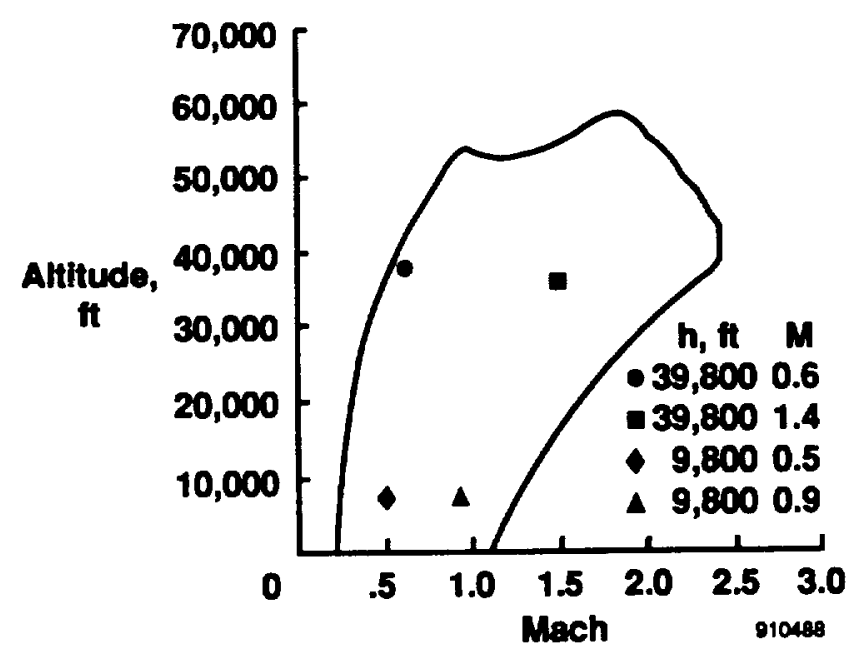

Fig. 3 Vehicle operational envelope at 45,000 lb.

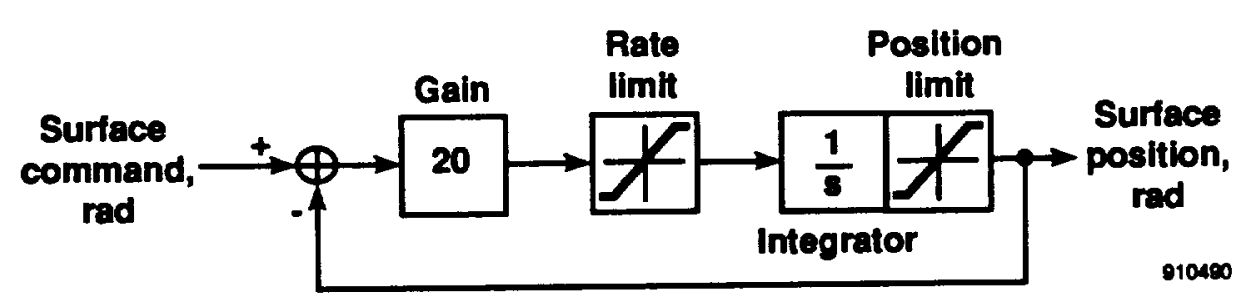

Fig. 4 Block diagram of actuator model.

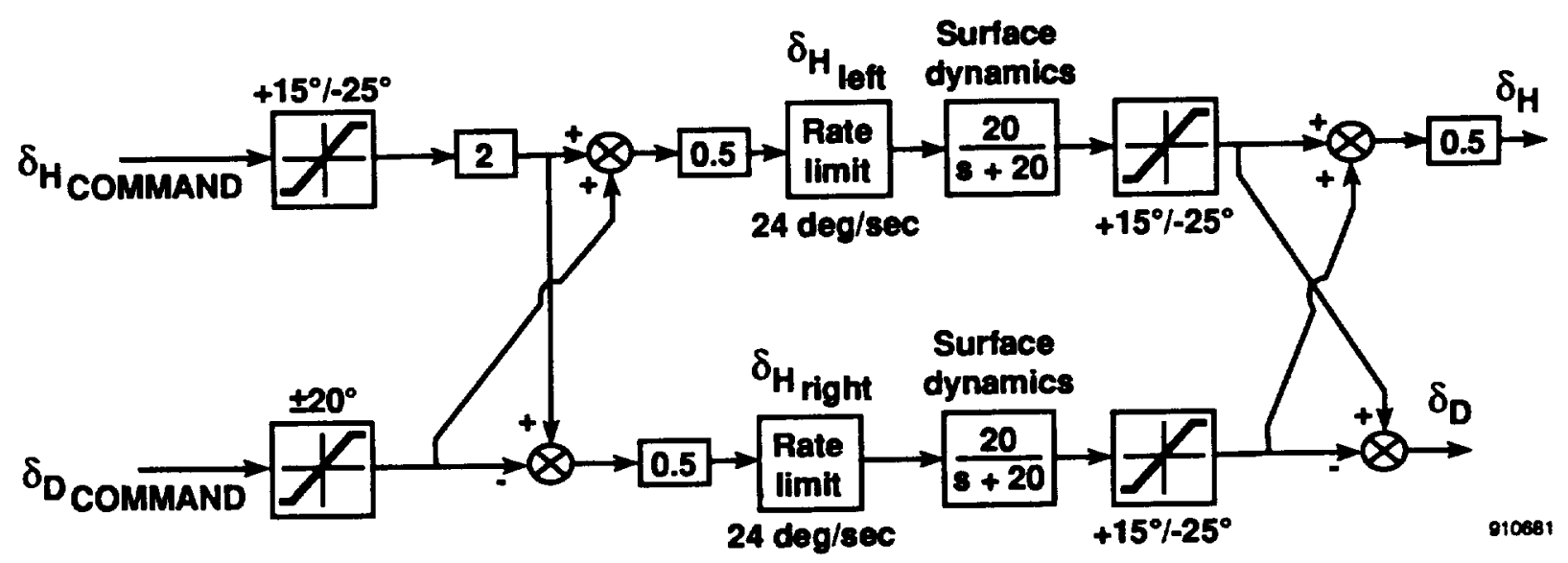

Fig. 5 Stabilator command path. 

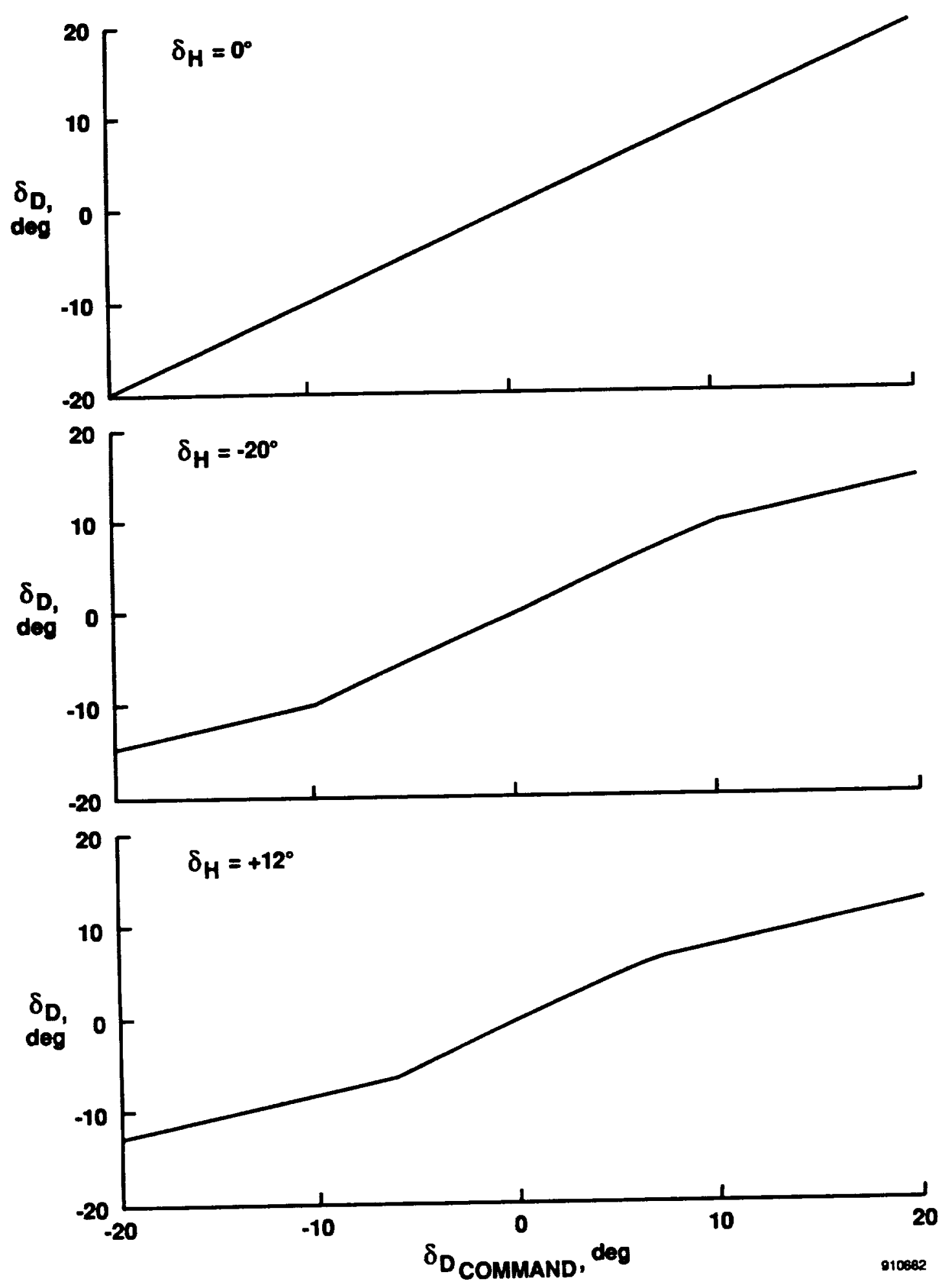

Fig. 6 Effect of $\delta_{H}$ on $\delta_{D}$ response. 

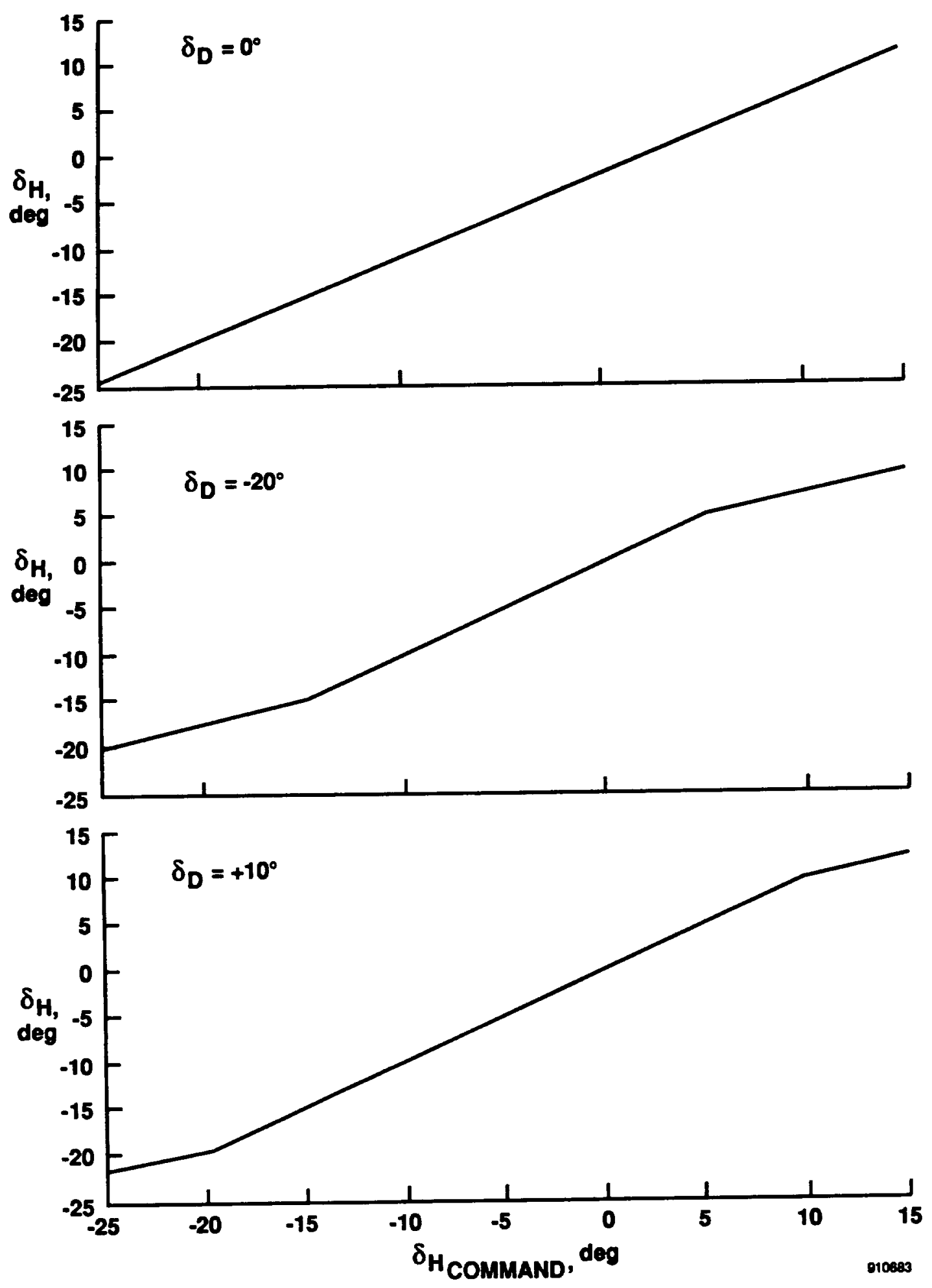

Fig. 7 Effect of $\delta_{\mathrm{D}}$ on $\delta_{\mathrm{H}}$ response. 
Table 4. Source of aerodynamic coefficients.

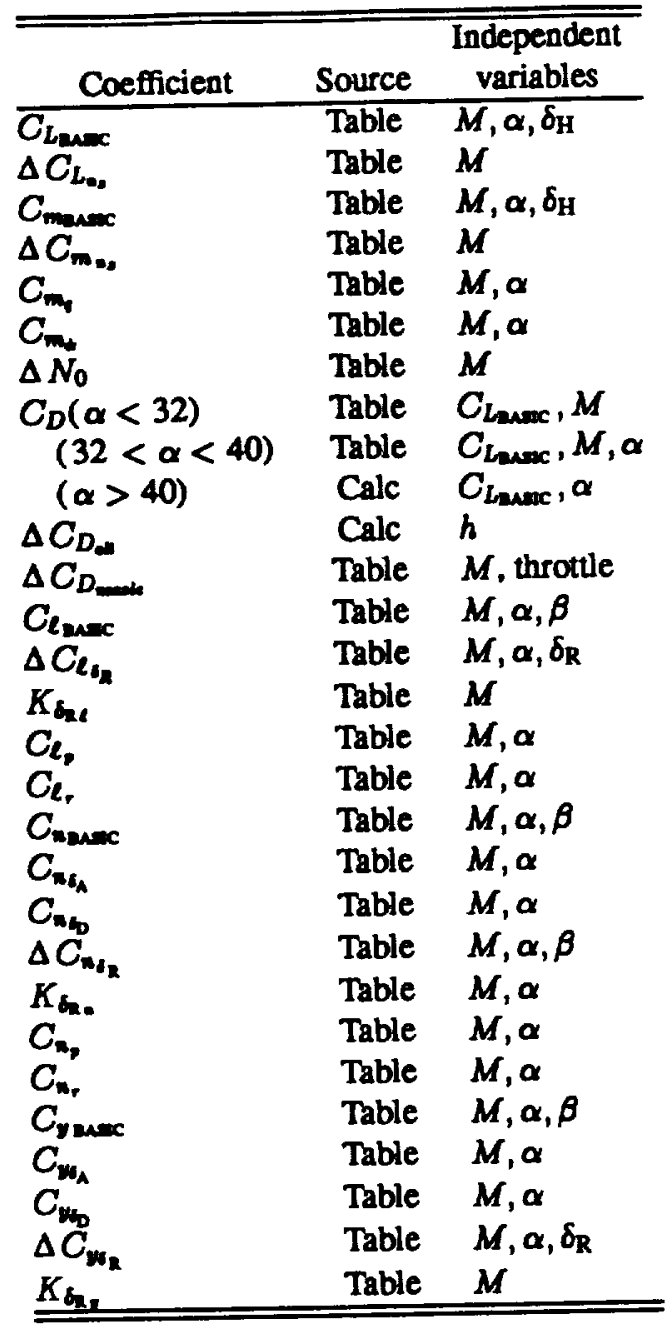

symmetrical. Each engine thrust vector is aligned with the body axis, and acts at a point located $10 \mathrm{ft}$ behind the vehicle center of gravity and $4 \mathrm{ft}$ laterally from the centerline. The thrust produced by each engine is a function of altitude $(h)$, $M$, and throttle setting. Each engine is modeled as a nonlinear system having two separate sections; a core engine and an afterburner (augmentor) section with associated sequencing logic.

Throttle position inputs to the engine model are in degrees, with a minimum position of $20^{\circ}$ and a maximum of $127^{\circ}$. The core section responds to throttle inputs up to $83^{\circ}$. The afterburner section begins to respond at a throttle position of $91^{\circ}$. The core model has first-order dynamics and rate limiting to model spool-up effects. A block diagram of the core model dynamics is shown in Fig. 8. The afterburner has a rate limiter and sequencing logic to model the fuel pump and pressure regulator effects. A block diagram of the afterburner model dynamics is shown in Fig. 9.

\section{Obeervation Model}

The observation variables provided by this model represent a broad class of parameters useful for vehicle analysis and control design problems. These variables include the state, time derivatives of state, and control variables. Airdata parameters, accelerations, fightpath terms, and other miscellaneous parameters are also included. The equations used to calculate those parameters are derived from a number of sources (Clancy, 1975; Dommasch et al., 1967; Etkin, 1972; Gainer and Hoffman, 1972; Gracy, 1980). Implicit in many of these observation equations is an atmospheric model. The atmospheric model is derived from the U.S. Standard Atmosphere (1962).

Three body axis angular rates and three translational accelerations are available as observation variables. These include the $x$-body axis rate $(u)$, the $y$-body axis rate $(v)$, and the $z$-body axis rate $(w)$. The time derivatives of these quantities, $\dot{u}, \dot{v}$, and $\dot{w}$ are also included. The equations defining these quantities are

$$
\begin{aligned}
& u=V \cos \alpha \cos \beta \\
& v=V \sin \beta \\
& w=V \sin \alpha \cos \beta \\
& \dot{u}=\left(\frac{X_{T}-g m \sin \theta-D \cos \alpha+L \sin \alpha}{m}\right)+r v-q w \\
& \dot{v}=\left(\frac{Y_{T}+g m \cos \theta \sin \phi+Y}{m}\right)+p w-r u \\
& \dot{w}=\left(\frac{Z_{T}+g m \cos \theta \cos \phi-D \sin \alpha-L \cos \alpha}{m}\right) \\
&+q u-p v
\end{aligned}
$$

The vehicle body axis accelerations constitute the set of observation variables that, except for state variables themselves, are most commonly used in aircraft control analysis and design problems. These accelerations are measured in $g$ units and are derived directly from the body axis forces defined in the previous section for translational acceleration. The equations used for the body axis acceleration $a_{x}, a_{y}$, and as are

$$
\begin{aligned}
& a_{x}=\left(X_{T}-D \cos \alpha+L \sin \alpha-g m \sin \theta\right) / 90 m \\
& a_{y}=\left(Y_{T}+Y+g m \cos \theta \sin \phi\right) / g 0 m \\
& a_{x}=\left(Z_{T}-D \sin \alpha-L \cos \alpha+g m \cos \theta \cos \phi\right) / 90 m
\end{aligned}
$$

where subscript 0 denotes standard day, sea level conditions. The equations for the outputs of the body axis accelerometers (denoted by subscript $n$ ) that are at vehicle center 


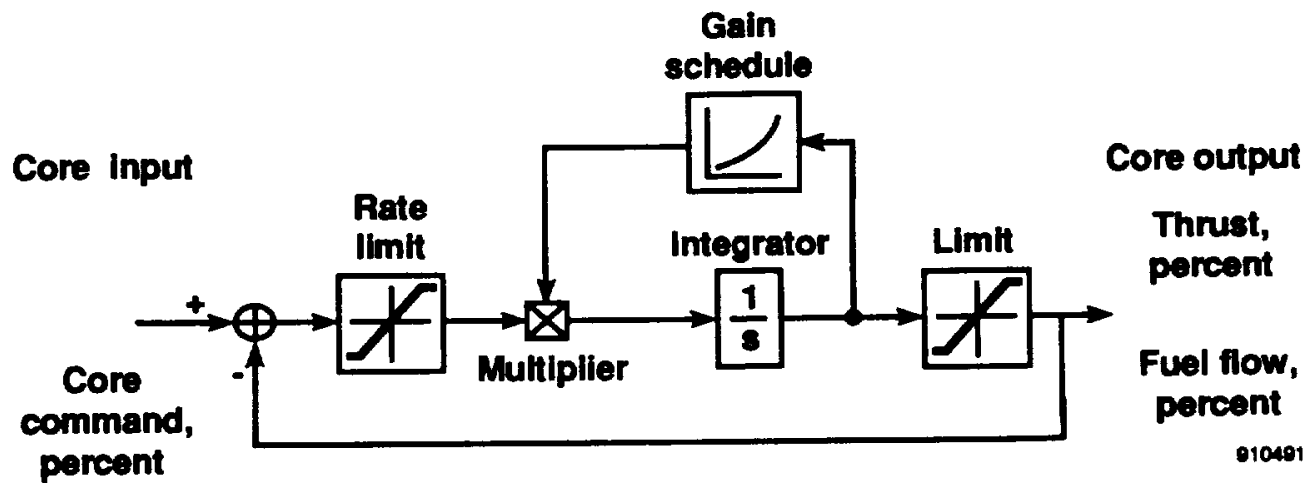

Fig. 8 First order engine core dynamics.

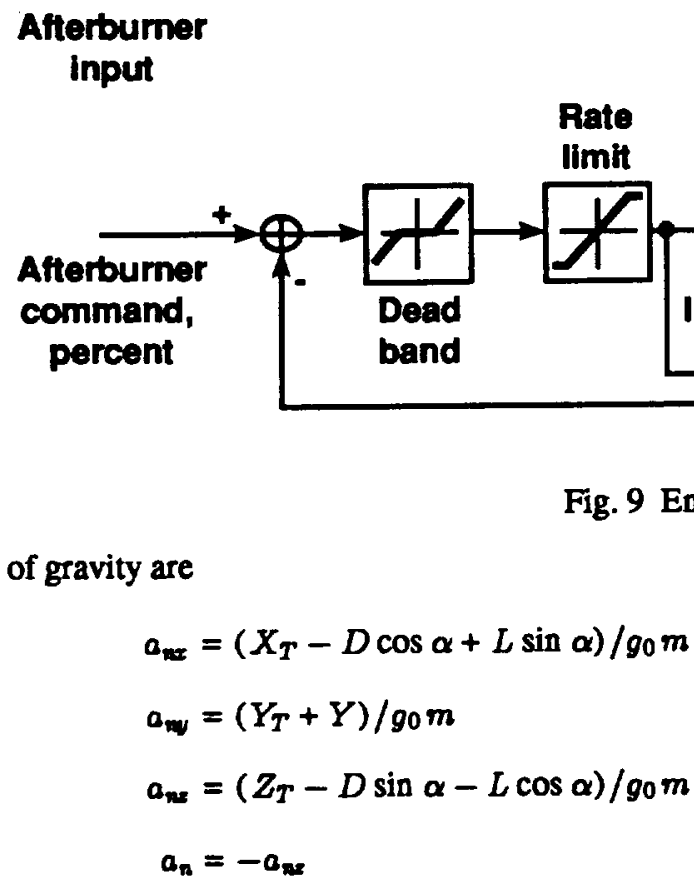

For orthogonal accelerometers that are aligned with the vehicle body axes but are not at vehicle center of gravity (denoted by subscript,$i)$, the following equations apply

$$
\begin{gathered}
a_{n x, i}=a_{n x}-\left[\left(q^{2}+r^{2}\right) x_{x}-(p q-\dot{r}) y_{x}\right. \\
\left.-(p r+\dot{q}) z_{x}\right] / g 0 \\
\begin{aligned}
a_{n y, i}=a_{n y}+ & {\left[(p q+\dot{r}) x_{y}-\left(p^{2}+r^{2}\right) y_{y}\right.} \\
+( & \left.(q r-\dot{p}) z_{y}\right] / g_{0}
\end{aligned} \\
a_{n x, i}=a_{n x}+\left[(p r-\dot{q}) x_{z}+(q r+\dot{p}) y_{z}\right. \\
\left.-\left(q^{2}+p^{2}\right) z_{x}\right] / g 0 \\
a_{n, i}=-a_{n x, i}
\end{gathered}
$$

where the subscripts $x, y$, and $z$ refer to the $x-, y-$, and $z$-body axes, respectively, and the symbols $x, y$, and $z$ refer to the $x-, y$-, and $z$-body axis locations of the sensors
Afterbumer output

Thrust, percent

Fuel flow, percent

910402

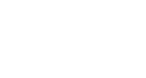

lag

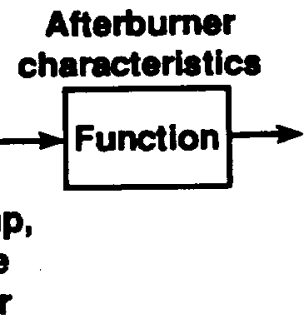

Fuel pump, pressure regulator 
The set of observation variables available also includes four force parameters; total aerodynamic lif $(L)$, total aerodynamic drag $(D)$, total aerodynamic normal force $(N)$, and total aerodynamic axial force $(A)$. These quantities are defined as

$$
\begin{aligned}
& L=\bar{q} S C_{L \text { sw }} \\
& D=\bar{q} S C_{D_{\text {min }}} \\
& N=L \cos \alpha+D \sin \alpha \\
& A=-L \sin \alpha+D \cos \alpha
\end{aligned}
$$

where $C_{D_{\text {mas }}}$ and $C_{\text {Lew }}$ are coefficients of drag and lift, respectively.

The airdata parameters having the greatest application to aircraft dynamics and control problems are the sensed parameters and the reference and scaling parameters. The sensed parameters are impact pressure $\left(q_{c}\right)$, ambient or freestream pressure $\left(p_{0}\right)$, total pressure $\left(p_{t}\right)$, ambient or freestream temperature $(T)$, and total temperature $\left(T_{t}\right)$. The selected reference and scaling parameters are Mach number $(M)$, dynamic pressure $(\bar{q})$, speed of sound (a), Reynolds number $(R e)$, Reynolds number per unit length ( $\left.R e^{\prime}\right)$, and the Mach meter calibration ratio $\left(g_{c} / p_{0}\right)$. These quantities are defined as

$$
\begin{aligned}
a & =\left(1.4 \frac{p_{0}}{\rho_{0} T_{0}} T\right)^{\frac{1}{2}} \\
M & =\frac{V}{a} \\
R e & =\frac{\rho V \ell}{\mu} \\
R e^{\prime} & =\frac{\rho V}{\mu} \\
\bar{q} & =\frac{\rho V^{2}}{2} \\
q_{c} & =\left\{\left[1.2 M^{2}\left(\frac{5.76 M^{2}}{5.6 M^{2}-0.8}\right)^{2.5}-1.0\right] p_{a}(M>1.0)\right. \\
p_{t} & =p_{a}+q_{c} \\
T_{t} & =T\left(1.0+0.2 M^{2}\right)
\end{aligned}
$$

where $\ell$ is length, $p$ pressure, $T$ is ambient of free-stream temperature, $\rho$ the density of the air, and $\mu$ the coefficient of viscosity. Free-stream pressure, free-stream temperature, and the coefficient of viscosity are derived from the U.S. Standard Atmosphere (1962).

Included in the airdata calculations are two velocities; equivalent airspeed $\left(V_{e}\right)$ and calibrated airspeed $\left(V_{c}\right)$, both computed in knots. The calculations assume that internal units are in the English system. The equation used for equivalent airspeed is

$$
V_{.}=17.17 \sqrt{\overline{9}}
$$

which is derived from the definition of equivalent airspeed,

$$
V_{c}=\sqrt{\frac{2 \bar{g}}{\rho_{0}}}
$$

where $\rho_{0}=0.002378$ slug/ $\mathrm{ft}^{3}$ and $V_{c}$ is converted from feet per second to knots. Calibrated airspeed is derived from the following definition of impact pressure

$q_{c}= \begin{cases}p_{0}\left[\left(1.0+\frac{p_{0}}{7 . p_{0}} V_{c}^{2}\right)^{3.5}-1\right] & \left(V_{c} \leq a_{0}\right) \\ 1.2\left(\frac{V_{c}}{\alpha_{0}}\right)^{2} p_{0}\left[\frac{5.76}{5.6-0.8\left(\omega_{0} / V_{c}\right)^{2}}\right]^{2.5}-p_{0}\left(V_{c}>a_{0}\right)\end{cases}$

For the case where $V_{c} \leq a_{0}$, the equation for $V_{c}$ is

$$
V_{c}=1479.116 \sqrt{\left(\frac{q_{c}}{p_{0}}+1.0\right)^{2 / 7}}-1.0
$$

Calibcated airspeed is found using an iterative process for the case where $V_{c}>a_{0}$

$V_{c}=582.95174 \sqrt{\left(\frac{q_{c}}{p_{0}}+1.0\right)\left[1.0-\frac{1.0}{7.0\left(V_{c} / a_{0}\right)^{2}}\right]^{2.5}}$

is executed until the change in $V_{c}$ from one iteration to the next is less than $0.001 \mathrm{kn}$.

The final set of observation variables provided is a miscellaneous collection of other parameters of interest in analysis and design problems. The first group consists of measurements from sensors not located at the vehicle center of gravity. These represent angle of attack $\left(\alpha_{, i}\right)$, angle of sideslip $\left(\boldsymbol{\beta}_{i}\right)$, altitude $\left(h_{, i}\right)$, and altitude rate $\left(\dot{h}_{, i}\right)$ measurements displaced from the center of gravity by some $x-, y$-, and $z$-body axis distances. The equations used to compute these quantities are

$$
\begin{aligned}
\alpha_{, i}= & \alpha-\left(\frac{q x-p y}{V}\right) \\
\beta_{, i}= & \beta+\left(\frac{r x-p z}{V}\right) \\
h_{, i}= & h+x \sin \theta-y \sin \phi \cos \theta-z \cos \phi \cos \theta \\
\dot{h}_{, i}= & \dot{h}+\dot{\theta}(x \cos \theta+y \sin \phi \sin \theta+z \cos \phi \sin \theta) \\
& -\dot{\phi}(y \cos \phi \cos \theta-z \sin \phi \cos \theta)
\end{aligned}
$$

The remaining miscellaneous parameters are total angular momentum $(T)$, stability axis roll rate $\left(p_{s}\right)$, stability axis pitch rate $\left(q_{0}\right)$, and stability axis yaw rate $\left(r_{s}\right)$, defined as 


$$
\begin{aligned}
& T=\frac{1}{2}\left(I_{x} p^{2}-2 I_{s y} P Q-2 I_{x z} p r+I_{y} q^{2}\right. \\
& \left.-2 I_{y z} q r+I_{s} r^{2}\right) \\
& p_{a}=p \cos \alpha+r \sin \alpha \\
& q_{s}=q \\
& r_{0}=-p \sin \alpha+r \cos \alpha
\end{aligned}
$$

\section{Equations of Motion and Atmospheric Model}

The nonlinear equations of motion used in this model are general six-degree-of-freedom equations representing the flight dynamics of a rigid aircraft flying in a stationary atmosphere over a flat, nonrotating Earth. These equations of motion were derived by Etkin, and the derivation is detailed in Duke, Antoniewicz, and Krambeer. The equations for each variable in the state vector are given in the following.

The following equations for rotational acceleration are used

$$
\begin{aligned}
\dot{p}= & {\left[(\Sigma L) I_{1}+(\Sigma M) I_{2}+(\Sigma N) I_{3}-p^{2}\left(I_{x z} I_{2}-I_{x y} I_{3}\right)\right.} \\
& +p q\left(I_{x z} I_{1}-I_{y z} I_{2}-D_{z} I_{3}\right) \\
& -p r\left(I_{x y} I_{1}+D_{y} I_{2}-I_{y z} I_{3}\right)+q^{2}\left(I_{y z} I_{1}-I_{x y} I_{3}\right) \\
& -q r\left(D_{x} I_{1}-I_{x y} I_{2}+I_{x z} I_{3}\right) \\
& \left.-r^{2}\left(I_{y z} I_{1}-I_{x z} I_{2}\right)\right] / \operatorname{det} I \\
\dot{q}= & {\left[(\Sigma L) I_{2}+(\Sigma M) I_{4}+(\Sigma N) I_{5}-p^{2}\left(I_{x z} I_{4}-I_{x y} I_{5}\right)\right.} \\
& +p q\left(I_{x z} I_{2}-I_{y z} I_{4}-D_{z} I_{5}\right) \\
& -p r\left(I_{x y} I_{2}+D_{y} I_{4}-I_{y z} I_{5}\right)+q^{2}\left(I_{y z} I_{2}-I_{x y} I_{5}\right) \\
& -g r\left(D_{x} I_{2}-I_{x y} I_{4}+I_{x z} I_{5}\right) \\
& \left.-r^{2}\left(I_{y z} I_{2}-I_{x z} I_{4}\right)\right] / \operatorname{det} I \\
\dot{r}= & (\Sigma L) I_{3}+(\Sigma M) I_{5}+(\Sigma N) I_{6}-p^{2}\left(I_{x x} I_{5}-I_{x y} I_{6}\right) \\
& +p q\left(I_{x z} I_{3}-I_{y z} I_{5}-D_{z} I_{6}\right) \\
& -p r\left(I_{x y} I_{3}+D_{y} I_{5}-I_{y z} I_{6}\right)+q^{2}\left(I_{y z} I_{3}-I_{x y} I_{6}\right) \\
& -q r\left(D_{x} I_{3}-I_{x y} I_{5}+I_{x z} I_{6}\right) \\
& \left.-\tau^{2}\left(I_{y z} I_{3}-I_{x z} I_{5}\right)\right] / \operatorname{det} I
\end{aligned}
$$

Where $\Sigma L, \Sigma M$ and $\Sigma N$ are the aerodynamic total moments about the $x-, y-$, and $z$-body axes, respectively, including power plant induced moments, and

$$
\begin{aligned}
\operatorname{det} I & =I_{x} I_{y} I_{z}-2 I_{x y} I_{x z} I_{y z}-I_{x} I_{y z}^{2}-I_{y} I_{x z}^{2}-I_{z} I_{x y}^{2} \\
I_{1} & =I_{y} I_{z}-I_{y z}^{2} \\
I_{2} & =I_{x y} I_{z}+I_{y z} I_{x z} \\
I_{3} & =I_{x y} I_{y z}+I_{y} I_{x z} \\
I_{4} & =I_{x} I_{z}-I_{x z}^{2} \\
I_{5} & =I_{x} I_{y z}+I_{x y} I_{x z} \\
I_{6} & =I_{x} I_{y}-I_{x y}^{2}
\end{aligned}
$$

$$
\begin{aligned}
& D_{x}=I_{z}-I_{y} \\
& D_{y}=I_{z}-I_{z} \\
& D_{z}=I_{y}-I_{z}
\end{aligned}
$$

The translational acceleration equations used are

$$
\begin{aligned}
\dot{V}=[ & -D \cos \beta+Y \sin \beta+X_{T} \cos \alpha \cos \beta \\
& +Y_{T} \sin \beta+Z_{T} \sin \alpha \cos \beta \\
& -m g(\sin \theta \cos \alpha \cos \beta-\cos \theta \sin \phi \sin \beta \\
& \quad-\cos \theta \cos \phi \sin \alpha \cos \beta)] / m \\
\dot{\alpha}= & -L+Z_{T} \cos \alpha-X_{T} \sin \alpha \\
& +m g(\cos \theta \cos \phi \cos \alpha+\sin \theta \sin \alpha)] / V m \cos \beta \\
& +g-\tan \beta(p \cos \alpha+r \sin \alpha) \\
\dot{\beta}=[ & D \sin \beta+Y \cos \beta-X_{T} \cos \alpha \sin \beta \\
& +Y_{T} \cos \beta-Z_{T} \sin \alpha \sin \beta \\
& +m g(\sin \theta \cos \alpha \sin \beta+\cos \theta \sin \phi \cos \beta \\
& \quad-\cos \theta \cos \phi \sin \alpha \sin \beta)] / V m \\
& +p \sin \alpha-r \cos \alpha
\end{aligned}
$$

where $\alpha, \beta, \theta$, and $\phi$ are angles of attack, sideslip, pitch, and roll, respectively; $X_{T}, Y_{T}$, and $Z_{T}$ are thrust along the $x-, y-$, and $z$-body axes; and $D$ is drag force, $g$ gravitational acceleration, $L$ total aerodynamic lift, $m$ total aircraft mass, $V$ total velocity, and $Y$ sideforce.

The equations defining the vehicle attitude rates are

$$
\begin{aligned}
& \dot{\theta}=q \cos \phi-r \sin \phi \\
& \dot{\psi}=q \sin \phi \sec \theta+r \cos \phi \sec \theta \\
& \dot{\phi}=q+q \sin \phi \tan \theta+r \cos \phi \tan \theta
\end{aligned}
$$

where $\psi$ is heading angle.

The equations defining the Earth-relative velocities are

$$
\begin{aligned}
\dot{h}=V( & \cos \beta \cos \alpha \sin \theta-\sin \beta \sin \phi \cos \theta \\
& -\cos \beta \sin \alpha \cos \phi \cos \theta) \\
\dot{x}=V[ & \cos \beta \cos \alpha \cos \theta \cos \psi \\
& +\sin \beta(\sin \phi \sin \theta \cos \psi-\cos \phi \sin \psi) \\
& +\cos \beta \sin \alpha(\cos \phi \sin \theta \cos \psi+\sin \phi \sin \psi)] \\
\dot{y}=V[ & \cos \beta \cos \alpha \cos \theta \sin \psi \\
& +\sin \beta(\sin \phi \sin \theta \sin \psi+\cos \phi \cos \psi) \\
& +\cos \beta \sin \alpha(\cos \phi \sin \theta \sin \psi-\sin \phi \cos \psi)]
\end{aligned}
$$

The atmospheric data model is based on tables from the U.S. Standard Atmosphere (1962). This model calculates values for speed of sound, acceleration due to gravity, air density, viscosity, and ambient static pressure and temperature. These values are calculated based on altitude. The 
tabular data is organized on evenly spaced breakpoints between 0 and $90 \mathrm{~km}$. Linear interpolation is used between table values for altitudes in this range; the extreme values are used for altitudes outside the range.

\section{FORTRAN Implementation}

The model is implemented as a program in standard FORTRAN 77 programming language. The program is intended to be portable, and has been successfully compiled on a wide range of computer platforms. The routines which implement the models are designed in a modular fashion, patterned after the modules described in the previous section. Modules communicate through named common blocks.

There are four primary subroutines; each corresponds to a primary module in the model. These routines are CCALC, ENGINE, INSTRM, and UCNTRL. The CCALC routine performs the calculations for the aerodynamic model. The UCNTRL routine, supplied by the user, calculates desired control surface deflections for the aerodynamic modeling routines. The INSTRM routine calculates the instrumentation models for the observation variables. The ENGINE routine contains the propulsion system model. These subroutines and associated common blocks are described in detail in the following subsections.

\section{Aircrant Characteristics}

Vehicle mass and geometry information is read from the file params.dat. These values are stored in the common block DATAIN as follows

\section{COMMON IDATAIN/S , B , CBAR, A SS, AIX , AIY, AIZ , AIXZ, ADXY, AIYZ, AIXE}

The first three variables in the common block, S, B, and CBAR, represent wing area, wingspan, and mean aerodynamic chord, respectively. The vehicle mass is represented by AMSS. The remaining values are vehicle inertias.

Equations of Motion and Atmospheric Model Routines

The routine DERIVC calculates the equations of motion, based on the previously listed model equations. The routine INTG integrates the equations to calculate the new state vector. The integration is performed using a second-order Runge-Kutta midpoint algorithm. Atmospheric model calculations are performed by the ALTFN routine.

\section{Aerodynamic Model Routines}

The aerodynamic model contains two major subroutines, ADATIN and CCALC. The subroutine ADATIN is used during initialization to input the basic formatted aerodynamic data from the file HPAS.dat. The subroutine CCALC uses this aerodynamic data, the state variables, and the surface positions to determine the aerodynamic coefficients. The CCALC subroutine is executed whenever new aerodynamic coefficients are required (for example, once each frame during a simulation).
The aerodynamic data are communicated from ADATWN to CCALC through named common blocks that occur in only these two routines. The interface between CCALC and the main program consists of several named common blocks that are used to pass state variables, airdata parameters, surface positions, and force and moment coefficients between CCALC and the calling program.

The main transfer of data into the subroutine CCALC is through named common blocks. These common blocks contain the state variables, airdata parameters, and surface positions. The transfer of output data from CCALC is through a named common block containing the aerodynamic force and moment coefficients. The details of these common blocks follow.

The common block DRVOUT contains the state variables and their derivatives with respect to time. The structure of this common block is shown in Table 5. The state variables

Table 5. Names and locations of state variables and derivatives in DERIVC common block.

\begin{tabular}{cccc}
\hline \hline Index & F & DF & Description \\
\hline 1 & T & TDOT & time \\
2 & P & PDOT & $p$ \\
3 & Q & QDOT & $q$ \\
4 & R & RDOT & $\boldsymbol{\tau}$ \\
5 & V & VDOT & velocity \\
6 & ALP & ALPDOT & $\alpha$ \\
7 & BTA & BTADOT & $\beta$ \\
8 & THA & THADOT & $\theta$ \\
9 & PSI & PSIDOT & $\psi$ \\
10 & PHI & PHIDOT & $\phi$ \\
11 & H & HDOT & $h$ \\
12 & X & XDOT & x position \\
13 & Y & YDOT & y position \\
\hline \hline
\end{tabular}

are stored first, in the $F$ array, and the derivatives follow in the DF array. Each array contains 13 elements. Routines which require access to these arrays use an EQUIVALENCE statement to allow access to the variables by the names shown in Table 5, for clarity. For example, the body axis rates $p, q$, and $r$ appear as $P, Q$, and $R$, respectively. Total velocity is represented by the variable $V$, and altitude by $\mathbf{H}$.

\section{COMMON /DERIVCI F(13), DF(13)}

The common block SIMOUT contains the main airdata parameters required for the function generation subroutine. The variables in this common block are

COMMON /SIMOUT/ AMCH, QBAR, GMA, DEL,
UB, VB, WB,
VEAS, VCAS


Mach number and dynamic pressure are the first entries in the common block, symbolized by AMCH and QBAR, respectively. The body axis velocities $u, v$, and $w$ are included as UB, VB, and WB, respectively.

Inputs to the actuator models are entered through the variables in the CONCOM common block, the structure of which is shown in the following

\section{COMMON /CONCOM/DAC, DHC, DRC, DDC}

The actuator model routine, ACTDYN, calculates the appropriate inputs to the aerodynamic model, based on the command inputs, and stores them in the CONTRL common block. The CONTRL common block contains the surface position and engine thrust information in the DC array. The structure of the common block/CONTRL is as follows

\section{COMMON /CONTRL/ DC (30)}

There are six locations in the DC array used. The definition of these is shown in Table 6. Routines which access these parameters usually EQUTVALENCE them to the variable names shown in the table.

Table 6. Names and locations of command inputs.

\begin{tabular}{cccc}
\hline \hline $\begin{array}{c}\text { Array } \\
\text { index }\end{array}$ & $\begin{array}{c}\text { Command } \\
\text { variable }\end{array}$ & $\begin{array}{c}\text { Position } \\
\text { variable }\end{array}$ & Function \\
\hline 1 & DAC & DA & $\delta_{\mathrm{A}}$ \\
5 & DHC & DH & $\delta_{\mathrm{H}}$ \\
8 & DDC & DD & $\delta_{\mathrm{D}}$ \\
9 & DRC & DR & $\delta_{\mathrm{R}}$ \\
11 & --- & & left engine thrust \\
12 & --- & & right engine thrust \\
\hline \hline
\end{tabular}

The common block SIMACC contains the accelerations, accelerometer outputs, and normal accelerometer output at the center of gravity of the aircraft.

COMMON /SIMACCI AX, AY, AZ,
ANX, ANY, ANZ,
AN

The output common block CLCOUT contains the variables representing the aerodynamic moment and force coefficients

\section{COMMON/CLCOUT/CL, CM, CN, CD, CLFT, CY}

The variables $\mathrm{CL}, \mathrm{CM}$, and $\mathrm{CN}$ are the symbols for the coefficients of rolling moment $\left(C_{\ell}\right)$, pitching moment $\left(C_{m}\right)$, and yawing moment $\left(C_{n}\right)$, respectively; these terms are body axis coefficients. The stability axis forces are represented by CD (coefficient of drag $C_{D}$ ), CLFT (coefficient of lift $C_{L}$ ), and $C Y$ (sideforce coefficient $C_{Y}$ ).

\section{Propulsion System Model Routines}

The top level subroutine ENGINE computes individual engine parameters to calculate force, torque, and gyroscopic effects caused by engine offset from the centerline. Each time ENGINE is called, it calls the interface routine UENGIN, which calls the actual engine model in the routine ENGMDL. After ENGMDL computes thrust from each engine, ENGINE uses the parameters in the ENGSTF common to compute force, torque, and gyroscopic effects. The control inputs to the engine model are THRSTX(1) for the left engine throttle position in degrees, and THRSTX(2) for the right engine. The THRSTX array is in the CTPARM common block. The output thrust is available in two locations; left engine thrust appears as DC(11), in the CONTRL common block, and as THRUST(1) in the ENGSTF common block. Similarly, right engine thrust appears as DC(12) and THRUST(2). Various other parameters used for calculation of engine effects are passed through common block ENGSTF as follows

COMMON /ENGSTF/ THRUST (4), TLOCAT $(4,3)$, XYANGL (4), XZANGL (4), TVANXY (4), TVANXZ (4), DXTHRS (4), EXX (4), AMSENG (4), ENGOMG (4)

The variables in this common block correspond to thrust (THRUST); the $x-, y-$, and $z$-body axis coordinates of the point at which thrust acts (TLOCAT); the orientation of the thrust vector in the $x-y$ body axis plane (XYANGL) in degrees; the orientation of the thrust vector in the $x-z$ body axis plane (XZANGL) in degrees; the orientation of the thrust vector in the $x-y$ engine axis plane (TVANXY) in degrees; the orientation of the thrust vector in the $x-z$ engine axis plane (TVANXZ) in degrees; the distance between the center-of-gravity of the engine and the thrust point (DXTHRS) measured positive in the negative $x$-engine axis; the rotational inertia of the engine (EIX); mass (AMSENG); and the rotational velocity of the engine (ENGOMG).

Although many of the engine arrays are sized to contain four elements, only the first two are used. The first element corresponds to the left engine, the second to the right engine. Engine data is contained in the file ENGINEdat, stored as formatted text.

\section{Observation Model Routines}

The common block OBSERV allows the user to access all the observation variables. This common block contains the two vectors OBSVEC(120) and PARAM $(120,6)$. A list of the available observations and parameters is given in Table 7. 
Table 7. Observation variables available in the OBSVEC array.

\begin{tabular}{|c|c|}
\hline $\begin{array}{l}\text { Location (index) } \\
\text { in OBSVEC }\end{array}$ & Variables \\
\hline \multicolumn{2}{|r|}{ State variables } \\
\hline 1 & Roll rate \\
\hline 2 & Pitch rate \\
\hline 3 & Yaw rate \\
\hline 4 & Velocity \\
\hline 5 & Angle of attack \\
\hline 6 & Angle of sideslip \\
\hline 7 & Pitch attitude \\
\hline 8 & Heading \\
\hline 9 & Roll attitude \\
\hline 10 & Altitude \\
\hline 11 & Displacement north \\
\hline 12 & Displacement east \\
\hline \multicolumn{2}{|c|}{ Derivatives of state variables } \\
\hline 13 & Roll acceleration \\
\hline 14 & Pitch acceleration \\
\hline 15 & Yaw acceleration \\
\hline 16 & Velocity rate \\
\hline 17 & Angle-of-attack rate \\
\hline 18 & Angle-of-sideslip rate \\
\hline 19 & Pitch attitude rate \\
\hline 20 & Heading rate \\
\hline 21 & Roll attitude rate \\
\hline 22 & Altitude rate \\
\hline 23 & Velocity north \\
\hline 24 & Velocity cast \\
\hline \multicolumn{2}{|r|}{ Accelerations } \\
\hline 25 & x-body axis acceleration \\
\hline 26 & $y$-body axis acceleration \\
\hline 27 & $z$-body axis acceleration \\
\hline 28 & $\begin{array}{l}x \text {-body axis accelerometer at vehicle } \\
\text { center of gravity }\end{array}$ \\
\hline 29 & $\begin{array}{l}y \text {-body axis accelerometer at vehicle } \\
\text { center of gravity }\end{array}$ \\
\hline 30 & $\begin{array}{l}z \text {-body axis accelerometer at vehicle } \\
\text { center of gravity }\end{array}$ \\
\hline 31 & Normal acceleration \\
\hline 32 & $\begin{array}{l}x \text {-body axis accelerometer not at } \\
\text { vehicle center of gravity }\end{array}$ \\
\hline 33 & $\begin{array}{l}y \text {-body axis accelerometer not } \\
\text { at vehicle center of gravity }\end{array}$ \\
\hline 34 & $\begin{array}{l}z \text {-body axis accelerometer not } \\
\text { at vehicle center of gravity }\end{array}$ \\
\hline 99 & $\begin{array}{l}\text { Normal accelerometer not } \\
\text { at vehicle center of gravity }\end{array}$ \\
\hline 98 & Load factor \\
\hline
\end{tabular}

Table 7. Continued.

\begin{tabular}{|c|c|}
\hline $\begin{array}{l}\text { Location (index } \\
\text { in OBSVEC }\end{array}$ & Variables \\
\hline \multicolumn{2}{|c|}{ Airdata parameters } \\
\hline 91 & Speed of sound \\
\hline 37 & Reynolds number \\
\hline 103 & $\begin{array}{l}\text { Reynolds number per } \\
\text { unit length }\end{array}$ \\
\hline 35 & Mach number \\
\hline 36 & Dynamic pressure \\
\hline 56 & Impact pressure \\
\hline 55 & Ambient pressure \\
\hline 57 & $\begin{array}{l}\text { Impact/ambient } \\
\text { pressure ratio }\end{array}$ \\
\hline 58 & Total pressure \\
\hline 59 & Temperature \\
\hline 60 & Total temperature \\
\hline 92 & Equivalent airspeed \\
\hline 93 & Calibrated airspeed \\
\hline \multicolumn{2}{|c|}{ Flightpath-related parameters } \\
\hline 39 & Flightpath angle \\
\hline 38 & Flightpath acceleration \\
\hline 40 & Flightpath angle rate \\
\hline 43 & Scaled altitude rate \\
\hline \multicolumn{2}{|c|}{ Energy-related terms } \\
\hline 46 & Specific power \\
\hline 47 & Specific energy \\
\hline \multicolumn{2}{|r|}{ Force parameters } \\
\hline 94 & Lift force \\
\hline 95 & Drag force \\
\hline 96 & Normal force \\
\hline 97 & Axial force \\
\hline \multicolumn{2}{|r|}{ Body axis parameters } \\
\hline 52 & $x$-body axis velocity \\
\hline 53 & $y$-body axis velocity \\
\hline 54 & $z$-body axis velocity \\
\hline 100 & $\begin{array}{l}\text { Rate of change of velocity in } \\
x \text {-body axis }\end{array}$ \\
\hline 101 & $\begin{array}{l}\text { Rate of change of velocity in } \\
y \text {-body axis }\end{array}$ \\
\hline 102 & $\begin{array}{l}\text { Rate of change of velocity in } \\
z \text {-body axis }\end{array}$ \\
\hline \multicolumn{2}{|c|}{$\begin{array}{l}\text { Miscellaneous measurements not } \\
\text { at vehicle center of gravity }\end{array}$} \\
\hline 44 & $\begin{array}{l}\text { Angle of attack not at } \\
\text { vehicle center of gravity }\end{array}$ \\
\hline 45 & $\begin{array}{l}\text { Angle of sideslip not at } \\
\text { vehicle center of gravity }\end{array}$ \\
\hline 41 & $\begin{array}{l}\text { Altitude instrument not at } \\
\text { vehicle center of gravity }\end{array}$ \\
\hline 42 & $\begin{array}{l}\text { Altitude rate instrument not } \\
\text { at vehicle center of gravity }\end{array}$ \\
\hline
\end{tabular}


Table 7. Concluded.

\begin{tabular}{cc}
\hline $\begin{array}{c}\text { Location (index) } \\
\text { in OBSVEC }\end{array}$ & Variables \\
\hline \multicolumn{2}{c}{ Other miscellaneous parameters } \\
\hline 48 & Vehicle total angular \\
& momentum \\
49 & Stability axis roll rate \\
50 & Stability axis pitch rate \\
51 & Stability axis yaw rate \\
\hline \multicolumn{2}{c}{ Control surface parameters } \\
\hline 61 to 90 & Control surfaces DC(1) \\
\multicolumn{3}{c}{ to DC(30) } \\
\hline \multicolumn{3}{c}{ Propulsion parameters } \\
\hline 107 & Throttle position - left engine \\
108 & Throttle position - right engine \\
\hline \hline
\end{tabular}

The observation vector is produced by the INSTRM routine, which contains calculations for instrumentation and observation models. The observation vector is in the OBSVEC array, in the OBSERV common block as follows

\section{COMMON /OBSERV/ OBSVEC(120), PARAM(120,6)}

The contents of the observation vector are strictly outputs from the simulation; none of the models use these values. The stored parameters were selected to provide a variety of useful information; however, several unused locations (OBSVEC(109) - OBSVEC(120)) are available for the user to include other observation variables. The user may also modify any of the locations without affecting the simulation. The PARAM array is used to store parameters which affect corresponding measurements in OBSVEC, such as the locations of an accelerometer not at the vehicle center of gravity.

\section{Interfacing and Using the Model as a Simulation}

This section describes the typical method of interfacing to and operating the simulation built from the FORTRAN implementation of the model. The information in this section is sufficient to allow a user to interface to the simulation and begin using it, without being concerned about the details of the model, equations, or the FORTRAN program.

The routine UCNTRL contains the user control law implementation. The inputs to this routine may be taken from any common block, but typically use the observation variables in the OBSVEC array, in the OBSERV common block. The OBSVEC array contains many parameters which would be unmeasurable on an actual aircraft; these should not be used as inputs to a practical control system. The outputs are the four control position commands in the CONCOM common block, and the two throttle settings, THRSTX, in the CTPARM common block. A simple autopilot is provided in the distribution UCNTRL as an example.
Routines for user supplied input and output are also provided. The routine URTIN is called at the start of each frame loop, to perform input. The routine URTOUT is called at the end of each loop to perform output tasks. These routines may perform any function the user wishes. They may contain file 10, interfaces to a network, a windowing system, or shared memory. Using these routines, the user may implement displays or recording capability and control the simulation. These routines are called in the main loop, so their execution will affect execution time significantly. Examples of these routines are provided in the distribution.

A routine is provided for user specified initialization, UINTT. This routine is called once, as the last step in the initialization sequence. Any initializations may be included here.

The simulation has three mutually exclusive modes of operation; operate, reset, and hold. The mode selection is performed by setting one of the variables, OPERAT, RESET, or HOLD to true, and resetting the remaining two variables to false. These variables are found in the common block SSSO01. Operate is the normal mode in which the simulation executes all the input, output, integration, and model routines. In hold mode, the simulation only executes the input and output routines; all states and parameters hold their last value. In reset mode, the simulation is reinitialized to the user specified initial conditions. The model routines are called, but no integrations are performed, so simulation time does not pass.

Initial conditions are specified in the array FIC, which contains a value for each of the 13 state variables. This array is in the common block SETICS. These values are copied into the state vector $(\mathrm{F})$ by the ICSET routine whenever the simulation is placed into reset mode. Default initial conditions are provided in the block data initialization, but a new set may be used at any time by setting the desired values in the FIC array and putting the simulation into reset mode.

\section{Concluding Remarks}

This paper describes a generic, state-of-the-art, highperformance aircraft model, including detailed, fullenvelope, nonlinear aerodynamics, and full-envelope thrust and first-order engine response data. While this model was primarily developed for the AIAA Controls Design Challenge, the availability of such a model provides a common focus for research in aeronautical control theory and methodology. This paper also describes an implementation of this model using the FORTRAN computer language, associated routines furnished with the aircraft model, and techniques for interfacing these routines to external procedures. Figures showing vehicle geometry, surfaces, and sign conventions are included. 


\section{References}

Clancy, L.J., Aeradynamics, John Wiley \& Sons, New York, NY, 1975.

Dommasch, Daniel O.. Sherby, Sydney S., and Connolly, Thomas F, Airplane Aerodynamics, Fourth Edition, Pitman, New York, NY, 1967.

Duke, E.L., Antoniewicz, R.F., and Krambeer, K.D., Derivation and Definition of a Linear Aincraft Model, NASA RP-1207, Aug. 1988.

Duke E.L., Patterson, B.P., Antoniewicz, R.F., User's Manual for LINEAR, a FORTRAN Program to Derive Linear Aincraft Models, NASA TP-2768, Dec. 1987.
Etkin, Bernhard, Dynamics of Atmospheric Flight, John Wiley Sons, New York, 1972.

Gainer, Thomas G. and Hoffman, Sherwood, Summary of Transformation Equations and Equations of Motion Used in Free-Flight and Wind-Tunnel Data Reduction and Analysis, NASA SP-3070, 1972.

Gracey, William, Measurement of Aircraft Speed and Altitude, NASA RP-1046, 1980.

U.S. Standard Atmosphere, 1962, U.S. Government Printing Office, Washington 25, D.C., 1962. 



\begin{tabular}{|c|c|c|c|}
\hline \multicolumn{3}{|c|}{ REPORT DOCUMENTATION PAGE } & $\begin{array}{l}\text { Form Approved } \\
\text { OMB No. 0704-0188 }\end{array}$ \\
\hline \multicolumn{4}{|c|}{ 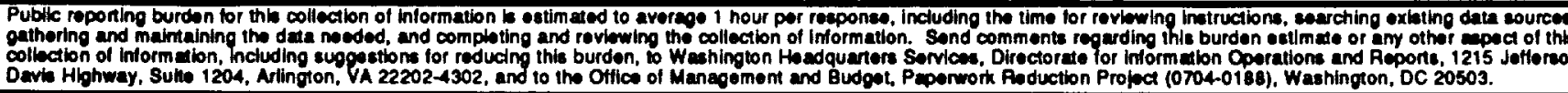 } \\
\hline 1. AGENCY USE ONLY (Loave blank) & $\begin{array}{l}\text { 2. REPORT DATE } \\
\text { December } 1991\end{array}$ & 3. $\stackrel{\text { P }}{N}$ & $\begin{array}{l}\text { DD DATES COVEAED } \\
\text { tor RepOrt }\end{array}$ \\
\hline \multicolumn{3}{|c|}{$\begin{array}{l}\text { 4. TITLE AND SUBtITLE } \\
\text { An Aircraft Model for the AIAA Controls Design Challenge }\end{array}$} & 5. FUNDING NUMBERS \\
\hline $\begin{array}{l}\text { 6. AUTHOR(S) } \\
\text { Randal W. Brumbaugh }\end{array}$ & & & RTOP 505-64-30 \\
\hline $\begin{array}{l}\text { 7. PERFORMING OAGANIZATION NAM } \\
\text { NASA Dryden Flight Researc } \\
\text { P.O. Box } 273 \\
\text { Edwards, Califomia } 93523-02\end{array}$ & $\begin{array}{l}\text { S) AND ADDRESS(ES) } \\
\text { Facility }\end{array}$ & & $\begin{array}{l}\text { 9. PERFORMING OAGANIZATION } \\
\text { REPORT NUMBER } \\
\text { H-1777 }\end{array}$ \\
\hline $\begin{array}{l}\text { 9. SPONSORING/MONITORING AGENC } \\
\text { National Aeronautics and Spa } \\
\text { Washington, DC 20546-0001 }\end{array}$ & $\begin{array}{l}\text { NAME(S) AND ADDAESS } \\
\text { Administration }\end{array}$ & & $\begin{array}{l}\text { 10. SPONSORING/MONITOAING } \\
\text { AGENCY REPORT NUMBER }\end{array}$ \\
\hline \multicolumn{4}{|c|}{$\begin{array}{l}\text { Prepared as AIAA 91-2631. Presented at the AIAA GNC Conference, New Orleans, } \\
\text { Louisiana, August 12, 1991. Technical monitor: Vince Chacon }\end{array}$} \\
\hline $\begin{array}{l}\text { 12a. DISTRIBUTION/AVAILABILITY ST } \\
\text { Unclassified - Unlimited } \\
\text { Subject Category } 05\end{array}$ & EMENT & & 12b. DISTRIBUTION CODE \\
\hline
\end{tabular}

13. ABSTRACT (Maximum 200 worda)

This paper describes a generic, state-of-the-art, high-performance aircraft model, including detailed, full-envelope, nonlinear aerodynamics, and full-envelope thrust and first-order engine response data. While this model was primarily developed for the AIAA Controls Design Challenge, the availability of such a model provides a common focus for research in aeronautical control theory and methodology. This paper also describes an implementation of this model using the FORTRAN computer language, associated routines fumished with the aircraft model, and techniques for interfacing these routines to external procedures. Figures showing vehicle geometry, surfaces, and sign conventions are included.

\begin{tabular}{|c|c|c|c|}
\hline \multicolumn{3}{|l|}{ 14. SUBJECT TERMS } & $\begin{array}{l}\text { 15. NUMBER OF PAGES } \\
19\end{array}$ \\
\hline Simulation; Controls; De & ign challenge; Model; Nume & ical simulation & $\begin{array}{l}\text { 16. PAICE CODE } \\
\mathrm{AO2}\end{array}$ \\
\hline $\begin{array}{l}\text { 17. SECURITY CLASSIFICATION } \\
\text { OF REPORT } \\
\text { Unclassified }\end{array}$ & $\begin{array}{l}\text { 18. SECURITY CLASSIFICATION } \\
\text { OF THIS PAOE } \\
\text { Unclassified }\end{array}$ & $\begin{array}{l}\text { 19. SECURITY CLASSIFICATION } \\
\text { OF ABSTRACT } \\
\text { Unclassified }\end{array}$ & $\begin{array}{l}\text { 20. LIMITATION OF ABSTRACT } \\
\text { Unlimited }\end{array}$ \\
\hline
\end{tabular}


